\title{
'End-of-life' decision making within intensive care - objective, consistent, defensible?
}

Andrew J Ravenscroft and M D Dominic Bell The General Infirmary at Leeds, Leeds

\begin{abstract}
Objective-To determine the objectivity, consistency and professional unanimity in the initiation, continuation and withdrawal of life-prolonging procedures in intensive care-to determine methods, time-scale for withdrawal and communication with both staff and relatives-to explore any professional unease about legality, morality or professional defensibility.

Design-A structured questionnaire directed at clinical nurse managers for intensive care.

Setting - All intensive care units in the Yorkshire region.

Results-The survey reported a lack of consistency and objectivity in decision making in this area, with accompanying unease amongst staff.

Conclusions-There is a need to work towards more consistent care, both before and during admission, for the protection of the individual patient and to allow rational assessment of intensive care need. Comprehensive audit should lead to objective defensible decisions and facilitate informed choice. More open debate and better communication should minimise this issue as a source of stress amongst staff in intensive care. (Fournal of Medical Ethics 2000;26:435-440)
\end{abstract}

Keywords: Euthanasia, passive; ethics, medical; critical care

\section{Introduction}

Technological advances have enabled intensive care facilities to support life during critical illness without modifying the underlying pathology or the process of dying. The challenge therefore, is less one of application of those techniques, and more on objective defensible decision making in the initiation, maintenance or withdrawal of support, not only for the patient's benefit, but to ensure effective and efficient use of a scarce resource.

This process is hindered by a lack of sound scientific evidence for many of the component activities, a lack of detailed outcome data for intensive care and uncertainty or different perspectives on the ethical principles underlying that care.

The National Health Service (NHS) executive sought to rationalise this process with the publication in March 1996 of explicit guidelines for care. ${ }^{1}$ These were based on the following principles: a) Intensive care is a service for patients with potentially recoverable conditions who can ben- efit from more detailed observation and invasive treatment than can safely be provided in general wards or high dependency areas.

b) Intensive care units should have clear operational policies based on multidisciplinary care, effective communication and consultant to consultant referral where possible.

c) Since intensive care may serve only to delay death rather than reverse the underlying pathology, the appropriateness of admissions should be considered in the light of such reversibility, associated comorbidity and the patient's stated or written preference against intensive care.

d) Once admitted, the appropriateness of continuing care should be made as soon as practicable after full discussion within the intensive care team, with the referring team and the patient and/or family.

e) A decision to limit treatment generates the options of discharge of the patient, making the patient comfortable or withdrawal of ventilatory support.

Although lacking detail, these guidelines do represent a distillation of accepted or published principles on the initiation, maintenance and withdrawal of care, involvement of the patient and family, and effective multidisciplinary communication.

\section{Objectives}

In our survey we sought to determine the extent to which the recommendations of the above report, ${ }^{1}$ had been implemented within our region and to establish how individual units approached the withdrawal of life-sustaining therapy.

\section{Methods}

A postal questionnaire was circulated to the clinical nurse managers of all intensive care units (ICUs) in the West Yorkshire region in June 1997. One follow up questionnaire was sent to non-respondents after three months.

The questionnaire sought information on 74 aspects on the following issues:

1. Admission to intensive care (numbers, death rates, refusal rates, scoring systems, admissions policy and medical support available for the unit). 
2. Decision making on withdrawal of lifeprolonging therapy (seniority, specialty, objectivity, consistency and standards of communication).

3. Mechanisms of withdrawal of life-prolonging therapy (methods, consistency, time-scale, documentation and the nursing role in implementation).

4. Concerns amongst the staff regarding this process (ethical, legal or professional defensibility).

5. Information provision for both patients and relatives.

The majority of questions involved fixed response answers (for example yes/no), the remainder being open-ended, requiring written responses.

Senior nursing staff were deliberately targeted, being considered accurate assessors of the actual process of care and more particularly, being directly involved in the immediate care of those patients for whom decisions on withdrawal of treatment had been made.

\section{Results}

Replies were received from 13 out of the 14 units circulated with the questionnaire.

Demography and medical staffing of ICUs

The bed-base ranged from three to 12 per unit, with admission numbers in 1996 ranging from 229 to 895 per unit.

The numbers of consultants with sessions dedicated to intensive care ranged from two to eight per unit. The total number of sessions covered by consultants per week ranged from five to 15 between units. (See table 1)

Units were asked whether or not they possessed data relating to patient outcome (table 2).

Nine units could provide mortality figures for patients on their unit, this varying from $20-30 \%$ Outcome data for patients once transferred or discharged was minimal.

Only one unit had data on refused admissions due to bed availability and no unit had information on numbers refused on the basis of inappropriateness.

Table 1 Medical cover for intensive care units

\begin{tabular}{ll}
\hline Dedicated ICU staff & Units \\
\hline Consultant 9-5pm & 9 \\
Consultant 5-9am & 6 \\
Junior 9-5pm & 8 \\
Junior 5-9am & 7 \\
\hline
\end{tabular}

Table 2 Number of units possessing patient mortality figures

\begin{tabular}{ll}
\hline Mortality & $\begin{array}{l}\text { No of units } \\
\text { with data }\end{array}$ \\
\hline On the unit & 9 \\
After transfer to other unit & 3 \\
After transfer to ward & 0 \\
Due to withdrawal of therapy & 0 \\
\hline
\end{tabular}

Table 3 Objectivity of the admission process

\begin{tabular}{|c|c|}
\hline Questions relating to objectivity & $\begin{array}{l}\text { Units } \\
\text { (yes answer) }\end{array}$ \\
\hline Formal written admission criteria? & 5 \\
\hline Criteria used to qualify refusal of admission? & 0 \\
\hline Admission refused on grounds of age? & 0 \\
\hline $\begin{array}{l}\text { Admission refused on grounds of specific pathology } \\
\text { for example HIV? }\end{array}$ & 0 \\
\hline $\begin{array}{l}\text { Formal assessment of premorbid health prior to } \\
\text { admission? }\end{array}$ & 1 \\
\hline $\begin{array}{l}\text { Formal assessment of premorbid health during } \\
\text { admission? }\end{array}$ & 3 \\
\hline APACHE scores recorded on admission? & 6 \\
\hline APACHE scores recorded daily during admission? & 0 \\
\hline Other scoring systems used (for example TISS)? & 4 \\
\hline
\end{tabular}

APACHE (Acute Physiology and Chronic Health Evaluation)

Two units subscribed to the national intensive care database at the Intensive Care National Audit and Research Centre (ICNARC).

\section{Admission process}

During the period 9-5 pm the ICU consultant was almost always responsible for confirming that an admission was appropriate (11/13). After hours (5-9 am), the responsibility for decisions of this nature was less explicit, and might fall to the consultant on call $(8 / 13)$, junior ICU staff $(4 / 13)$ or junior anaesthetist $(5 / 13)$.

Questions relating to the objectivity of admission decisions required yes or no answers (table 3 ).

Five respondents felt there was inconsistency in the admission process, citing lack of consultant input (3/13), pressure from parent specialty $(5 / 13)$ and new junior staff $(3 / 13)$ as possible reasons. The parent specialty had the final say on admission to the ICU in four of the 13 units.

Only six units had dedicated 24-hour consultant cover. Of these six units, three reported inconsistency in "decisions to admit", and only one had written guidelines for admission.

Patients could be refused admission should the nursing staff feel it inappropriate in one unit, and due to a lack of nursing staff in eight units.

Only four respondents were aware of a formal do-not-resuscitate (DNR) policy within their hospital.

Only five units considered there was any attempt in their hospital to determine the patient's wishes with regard to provision of intensive care prior to deterioration of the patient to a critical level.

\section{Consideration of when to withdraw life support}

No unit employed any formal guidelines for withdrawal of life-prolonging medical interventions.

Although six units recorded the nursing estimate of the probability of dying in the ICU register, only three had data on the accuracy of those predictions, this being between 60 and $70 \%$ over a year period. 
Table 4 Examples of inconsistency in withdrawal decisions

\begin{tabular}{ll}
\hline $\begin{array}{l}\text { Questions relating to inconsistency in the withdrawal } \\
\text { process }\end{array}$ & $\begin{array}{l}\text { Units } \\
\text { (yes answer) }\end{array}$ \\
\hline $\begin{array}{l}\text { Withdrawal of care appears premature? } \\
\text { There is inconsistency in withdrawal decisions for } \\
\text { patients with similar pathologies for example } \\
\text { chronic obstructive pulmonary disease? }\end{array}$ & 7 \\
$\begin{array}{l}\text { Withdrawal of care takes place for the purpose of } \\
\text { creating bed availability? }\end{array}$ & 9 \\
$\begin{array}{l}\text { Access to beds is denied due to inappropriate delay } \\
\text { in withdrawal of support? }\end{array}$ & 1 \\
$\begin{array}{l}\text { Family pressure to maintain support influences } \\
\text { decisions? }\end{array}$ & 8 \\
$\begin{array}{l}\text { Family pressure to withdraw support influences } \\
\text { decisions? }\end{array}$ & 11 \\
$\begin{array}{l}\text { Decisions are made on arbitrary quality of life } \\
\text { (QOL) judgments? }\end{array}$ & 10 \\
$\begin{array}{l}\text { Active treatment is continued despite nursing } \\
\text { perception of futility? }\end{array}$ & 9 \\
\hline
\end{tabular}

Five units were of the opinion that once the patient was admitted, the perceived outcome altered the management. None of these five units had admission protocols.

Eight respondents perceived medical decisions on withdrawal of care as inconsistent, with examples of inconsistency listed in table 4 .

Only four units claimed consistency of opinion between the ICU consultants, or between senior and junior ICU staff, with only three identifying consistency between ICU staff and parent specialty.

Only one unit engaged in a formal case conference for this activity.

Respondents indicated on what criteria they felt decisions to withdraw support were based (table 5).

On occasions active life-prolonging treatment was continued despite a medical perception of a hopeless outcome following disagreement on the part of the nursing staff (4/13); to allow more time for relatives to adjust to the situation $(12 / 13)$; because of the relatively young age of the patient (7/13), or when it wouldn't have been continued if there was more pressure on beds (3/13).

\section{Communication}

Responsibility for communicating general news to relatives was shared by the ICU consultant, ICU junior, or the parent specialty consultant. Communication regarding futility and withdrawal was most often undertaken by the ICU consultant (table 6 ). "Futility" refers to the situation whereby active support is only serving to delay the timing, rather than influencing the inevitability, of death from the patient's currently life-threatening pathology.

Table 5 Most common reasons for withdrawal of therapy

\begin{tabular}{lc}
\hline Reasons for withdrawal & Units \\
\hline Multiple organ failure & 10 \\
Unresponsive to treatment & 11 \\
Underlying diagnosis & 9 \\
Perceived quality of life & 8 \\
Failure to wean from ventilatory support & 4 \\
\hline
\end{tabular}

Table 6 Specialty and grade of medical staff involved in communicating with patient's relatives

\begin{tabular}{lcc}
\hline Medical Staff involved & General & Communication \\
\hline ICU consultant & 13 & 13 \\
ICU junior & 10 & 3 \\
Parent consultant & 9 & 7 \\
Parent junior & 4 & 1
\end{tabular}

Communication between medical staff and the patient's family occurred daily in eight units, but was reported as usually being initiated by a request from the nursing staff $(12 / 13)$ or family $(11 / 13)$.

In six units the nursing staff routinely primed the family with regard to futility prior to any medical interview and, in all but two units, nurses had received formal training for this role.

Most units felt they had an appropriate environment in which communication could take place. Only one unit regularly involved a professional facilitator or chaplain. In all units it was felt that relatives had adequate opportunity to ask questions.

A decision to withdraw therapy invariably involved discussion with family, nursing staff and the parent specialty. Although the family were always thoroughly informed with regard to the rationale for withdrawal of therapy, this did not always extend to the technique of withdrawal (9/13).

Although most units provided information booklets for relatives, none of these included considerations as to futility or withdrawal of care.

In seven units communication with relatives did not routinely introduce a time-scale for decision making, for example "if the patient is not improving in 72 hours, we will have to consider the merits of continuing treatment”.

In those that did, the time-scale varied between 24-72 hours, and between consultants within an individual unit.

Three units reported that at times, communication provided limited information in the interests of protecting the family or of effecting withdrawal of supportive therapy.

The content of communication was usually documented within the medical notes, and always in the nursing records.

\section{Methods of withdrawal of life support}

No unit had protocols for cessation of therapy once futility had been recognised.

All of the 13 units considered it appropriate to withdraw renal, ventilatory and cardiovascular support and to reduce the inspired oxygen concentration to that of room air. Five units considered it appropriate to withdraw nutritional or fluid therapy.

Eleven respondents stated that these methods varied from doctor to doctor, patient to patient and in three units according to bed availability or demand.

If a decision had been made to withdraw life-prolonging support from the patient, and 
Table 7 Techniques used in withdrawing support

\begin{tabular}{ll}
\hline Methods of terminal care employed & Units \\
\hline Weaning from ventilatory support and extubation & 12 \\
No increase in supportive therapy & 13 \\
Transfer of patient to primary ward area & 7 \\
$\begin{array}{l}\text { Provision of analgesia and sedation above current } \\
\text { requirements }\end{array}$ & 7 \\
$\begin{array}{l}\text { Withdrawal without an increase in analgesia or } \\
\text { sedation }\end{array}$ & 4 (but rarely) \\
\hline
\end{tabular}

analgesic or sedative drugs used sufficiently to ensure their comfort during this process, the family were made aware of this in all but one unit.

In most units the nursing staff worked within strict medical prescriptions, with only three allowing some degree of nursing autonomy in effecting withdrawal. The extent of patient monitoring and documentation of the process were reportedly variable.

The time-scale for both complete withdrawal and for death to take place depended on patient and family factors. These included the patient's pathology, time for family members to attend before death, and time to allow for their psychological adjustment.

\section{Concerns}

Respondents were not asked to distinguish between what they intended and what they merely foresaw.

Four respondents considered there to be no difference between active euthanasia and the administration of analgesic and sedative drugs in dosages that might hasten death, even if these drugs were given primarily to ensure patient comfort after withdrawal of ventilatory support. Four different respondents considered there to be no difference between passive euthanasia and withdrawal of support resulting in death of the patient.

In seven units, the legality, morality and documentation of withdrawal of therapy, along with their own professional accountability were all issues that concerned the nursing staff.

Every unit considered there to be a need for more open discussion within the public domain, with seven respondents supporting the role of living wills.

Twelve of the 13 respondents considered it essential that more open discussion take place within the nursing, medical and legal professions with regard to these issues.

\section{Discussion}

This survey, based on the perceptions of senior nursing staff, has demonstrated inconsistency and concern in all the key areas examined.

Inconsistency in the admission process may be attributable to a lack of formal policy, lack of consultant input, and changing responsibility for decision making out of hours.

Allocated consultant sessions and the level of dedicated medical cover falls short of the official guidelines, ${ }^{1-3}$ and is a possible contributory factor.
Inconsistency was, however, reported most amongst the units with recommended manpower levels, suggesting that other issues may need to be addressed.

Formal assessments of the patients' premorbid health and QOL (quality of life) were performed prior to admission in only one unit, and following admission in only three units. This is clearly inadequate, as such information is highly relevant when considering the appropriateness of admission. ${ }^{1}$

There are difficulties in quantifying health status based on patient's or relative's subjective opinion, and more precise measures are essential to aid decision making. Existing tests of functional status have been shown to be strong predictors of mortality after hospitalisation, ${ }^{4}$ but only if performed prior to a deterioration in the patient's condition.

It has to be accepted that for certain patients, life-sustaining treatments are often necessary to permit full evaluation and assessment of what can realistically be achieved. Explicit goals should then be set for response to treatment within an appropriate time-frame. A covert approach, whereby once admitted the patient's perceived outcome influences management, does not represent a satisfactory alternative.

Most units did not formally establish patients' or relatives' wishes with regard to the provision of intensive care prior to admission. This was compounded by scant awareness of existing DNR policies within hospitals and variation of opinion on the validity of "living wills".

Such an informal approach to these controversial issues could have serious legal implications..$^{6-10} \mathrm{~A}$ structured approach has been shown to have the additional benefit that staff feel more comfortable in discussing terminal care decisions with patients and relatives. ${ }^{11}$

Comprehensive audit activity in the units surveyed was deficient, with a paucity of accurate information on patient outcome and refusal of admission.

Risk adjustment methods such as APACHE were recorded by less than half the units, and may reflect the lack of evidence to support their use in deciding on whether to admit, or as predictors of outcome. ${ }^{12-15}$ However, scoring systems can support the decision making process, and provide useful audit information. ${ }^{16}$

More objective guidance for decision making would be beneficial but this goal can only be achieved by the development of a larger and more comprehensive database for outcomes of intensive care activity. The only national database ultimately capable of generating such information, ICNARC, suffers from the low subscription rates reflected in our results (personal communication: Kathy Rowan, ICNARC, March 1999).

The survey also revealed inconsistency in decisions on when and how to withdraw life-prolonging support, and in the level of communication amongst the staff and family involved. 
None of the units had agreed guidelines for cessation of therapy, and this can only accentuate the variation in practice that is driven by personal belief. Inconsistency may reflect discomfort and uncertainty with an aspect of care for which the individuals are not trained. ${ }^{17-22}$

Inconsistency impacts not only on patients and their families but also on the multidisciplinary team. In over half the units, nursing staff harboured concerns over legality, morality, ethics, and their own professional accountability. In the same units, respondents also felt that medical decisions to withdraw support varied between different medical staff and between patients with similar pathologies. It must be recognised that nursing staff work within a different professional framework from that of doctors. Precedents have been set whereby nurses have been suspended for following medical instructions, even for an act considered justified by the family. ${ }^{23}$ The nursing regulatory body, the United Kingdom Central Council for Nursing, Midwifery and Health Visiting (UKCC), does not produce guidelines on this subject, but does emphasise the importance of local policies, based on best practice, to promote consistency and avoid professional unease. ${ }^{24}$

\section{Major concern}

A major concern must be that in an era of both clinical governance and public scrutiny, there is little evidence of explicit operational policy or compliance with the recommendations. Since the legal and ethical principles of withdrawal of support and the distinction of this from euthanasia, have received extensive coverage in the medical and lay press, ${ }^{95-27}$ defensible consistent management within intensive care should be achievable.

More recently, (after our survey), the BMA medical ethics committee has sought to clarify these issues with the publication of a guidance document, Withholding and Withdrawing LifeProlonging Medical Treatment, ${ }^{10}$ which aimed "to provide a coherent and comprehensive set of principles which apply to all decisions". These guidelines emphasise the importance of advance management plans for progressive pathology, a thorough appraisal of the patient's underlying condition and a determination of the views of relatives to clarify what the patient would have considered beneficial in circumstances where the patient himor herself is not competent. This endorses not only best practice but also an ethical responsibility to use resources effectively and efficiently by not embarking on care of no benefit to the patient. These principles are in line with those previously documented, but are at variance with the standard of preadmission care identified by the survey. Following admission, the importance of communication, the team role in decision making, and structures and strategy to relieve misgivings or conflict receive due emphasis, the latter process clearly overdue in the light of our findings. The guidance on withdrawal decisions is explicit for the situation where a patient is actively deteriorating despite escalating cardio- vascular and respiratory support. The guidelines are less explicit for those cases where death could be indefinitely postponed by continuing support, but where judgments are made on the basis of previous limitations in health, presumed cognitive or functional deficits in the event of survival beyond ICU, or a potentially prolonged weaning process. These considerations are the ones that generate disquiet and cannot be comfortably categorised within the group where treatment has "ceased to be of benefit to the patient". Of greater relevance, however, is a lack of guidance on the provision of analgesia and sedation once a decision on withdrawal has been taken, and in particular, on subsequent withdrawal of ventilatory support: "consideration must be given to the continuing residual effect of suppressing the patient's ability to breathe unaided. Failure to do so could be interpreted, in law, as action taken with the purpose or objective of ending the patient's life". Most ICU staff would consider it appropriate to pre-empt any discomfort or distress prior to such action not only for the patient's benefit but also for attendant relatives, and the document introduces a divisive interpretation of this approach.

These considerations, taken in conjunction with the practice style and concerns identified by the survey, would suggest that intensive care practitioners are vulnerable to scrutiny, potentially leading to criminal or professional proceedings. The failure of the guidelines to define both active and passive euthanasia and to clarify the difference between these and the end-of-life activity described in this survey, will not help to dispel the uncertainties identified, rendering the above process more likely.

\section{Conclusions}

The variation in intensive care practice we have highlighted is multifactorial and not peculiar to the region surveyed ${ }^{28}$ or indeed to Britain. ${ }^{17}$ Factors driving this include pressure from patients, relatives and referring clinicians, medico-legal concerns or the simple employment of new technologies. ${ }^{18}$

The challenge for the professional credibility of all involved in intensive care, is to make consistent, objective and morally and legally justified decisions regarding the provision and withdrawal of lifeprolonging treatment.

Established ethical and legal principles and available professional guidelines do provide a sufficiently robust framework to achieve this goal.

The survey results therefore, have administrative implications for those individual units, which, contrary to those guidelines, do not have clear policies on the above components of care and do not achieve consistency between staff and individual patients with similar pathologies.

An obvious area for attention is the absence of accurate assessment of premorbid health and QOL, and more comprehensive audit of outcome.

The patient and family would also clearly benefit from information booklets to help them understand the principles of care and to enable them to participate in early and more informed decision making. 
The recent BMA guidelines constitute a significant step forward and promote many aspects of good practice relevant to intensive care, but may follow the above disturbing pattern of not being translated into improvements in care. It should also be noted that they lack the requisite specificity or clarity in key areas, necessitating further debate to avoid polarisation of views and damaging test cases.

With more extensive discussion, and acceptance of the underlying legal and ethical principles, it should be possible, however, to provide rational and consistent terminal care to the patient, minimise the concerns of staff, and improve the efficient use of this limited and expensive resource.

\section{Acknowledgement}

We thank Kathy Rowan of ICNARC for her critical evaluation and assistance.

Andrew $\mathcal{F}$ Ravenscroft, $M B C h B, F R C A$, is Specialist registrar - Intensive Care, The General Infirmary at Leeds, Department of Anaesthesia and Intensive Care, $D$ Floor, Fubilee Building, Great George Street, Leeds, LS1 3EX. M D Dominic Bell, MBChB, FRCA, is Consultant - Intensive Care in the same department. Correspondence to $\operatorname{Dr} M D D$ Bell.

\section{References}

1 NHS Executive Working Party. Guidelines on admission to and discharge from intensive care and high dependency units. London: Department of Health, Mar 1996.

2 Intensive Care Society. The intensive care service in the UK London: Intensive Care Society, 1990.

3 The Association of Anaesthetists of Great Britain and Ireland. Intensive care services provision for the future. London: The Association of Anaesthetists of Great Britain and Ireland, 1988

4 Inouye SK, Peduzzi PN, Robinson JT, Hughes JS, Horwitz RI, Concato J, et al. Importance of functional measures in predicting mortality among older hospitalised patients. fournal of the American Medical Association 1998;279:187-93.

5 Murray LS, Teasdale GM, Murray GD, Jennett B, Miller JD, Pickard JD, et al. Does prediction of patient outcome alte patient management? Lancet 1993;341:1487-91.

6 Luttrell S. Living wills do have legal effect [letter]. British Medical fournal 1996;313:1148.

7 Francis R. A legal comment. British Medical fournal 1995;310: 718 .

8 Dyer C. Living wills put on statutory footing. British Medical fournal 1998;316:9.

9 Task Force on Ethics of the Society of Critical Care Medicine. Consensus report on the ethics of foregoing life-sustaining treatments in the critically ill. Critical Care Medicine 1990;18:1435-9.
10 British Medical Association. Withholding and withdrawing life-prolonging treatment: guidance for decision making. London: British Medical Association. 1999.

11 Koch KA, Rodeffer HD, Wears RL. Changing patterns of terminal care in an intensive care unit. Critical Care Medicine 1994:22:233-43.

12 Chang RWS, Jacobs S, Lee B. Predicting outcome among intensive care unit patients using computerised trend analysis of daily Apache 11 scores corrected for organ system failure. Intensive Care Medicine 1988;14:558-66.

13 Chang RWS, Jacobs S, Lee B, Pace N. Predicting deaths among intensive care unit patients. Critical Care Medicine 1988;16:3442.

14 Knaus WA, Wagner DP, Draper EA, Zimmerman JE, Bergner $\mathrm{M}$, Bastos PG, et al. The APACHE 111 prognostic system. Risk prediction of hospital mortality for critically ill hospitalized adults. Chest 1991;100:1619-36.

15 Jacobs S, Arnold A, Clyburn PA, Willis BA. The Riyadh intensive care program applied to a mortality analysis of a teaching hospital intensive care unit. Anaesthesia 1992;47:775-8.

16 Boyd O, Ground RM. Physiological scoring systems and audit. Lancet 1993;341:1573-4.

17 Vincent JL. European attitudes towards ethical problems in intensive care medicine: results of an ethical questionnaire. Intensive Care Medicine 1990;16:256-64.

18 Osborne ML. Physician decisions regarding life support in the intensive care unit. Chest 1992;101:217-24.

19 The Society of Critical Care Medicine Ethics Committee. Attitudes of critical care medicine professionals concerning foregoing life-sustaining treatments. Critical Care Medicine 1992;20: 320-6.

20 Caralis PV, Hammon JS. Attitudes of medical students, housestaff, and faculty physicians towards euthanasia and termination of life-sustaining treatment. Critical Care Medicine 1992;20:683-90.

21 Wanzer SH, Federman DD, Adelstein SJ, Cassel CK, Cassem $\mathrm{EH}$, Cranford RE, et al. The physician's responsibility toward hopelessly ill patients. A second look. New England fournal of Medicine 1989;320:844-9.

22 Brody H, Campbell ML, Faber-Langendoen K, Ogle KS. Withdrawing intensive life sustaining treatment. Recommendations for compassionate clinical management. New England fournal of Medicine 1997;27:652-7.

23 Kellet JM. An ethical dilemma. A nurse is suspended. British Medical fournal 1996;313:1249-51.

24 United Kingdom Central Council for Nursing, Midwifery, and Health Visiting. Code of professional conduct for the nurse, midwife and health visitor [3rd ed]. London: UKCC, 1992.

25 Bone RC, Rackow EC, Weg JG and members of the ACCP/SCCM Consensus Panel. Ethical and moral guidelines for the initiation, continuation and withdrawal of intensive care. Chest 1990;97:949-58

26 Bion JF. Treatment limitation decisions. Current Topics in Intensive Care. 1995;2:102-24.

27 Meisel A. Legal myths about terminating life support. Archives of Internal Medicine 1991;151:1497-502.

28 Metcalfe MA, McPherson K. Study of intensive care in England. London: Department of Health, 1995. 